\title{
Erratum to: Sepsis in standard care: patients' characteristics, effectiveness of antimicrobial therapy and patient outcome-a cohort study
}

\author{
Franz Ratzinger ${ }^{1} \cdot$ Katharina Eichbichler $^{2} \cdot$ Michael Schuardt $^{2} \cdot$ Irene Tsirkinidou $^{2}$ • \\ Dieter Mitteregger $^{3}$ Helmuth Haslacher ${ }^{1}$ - Thomas Perkmann ${ }^{1}$. \\ Klaus G. Schmetterer ${ }^{1}$ - Georg Dorffner ${ }^{4} \cdot$ Heinz Burgmann ${ }^{2}$
}

Published online: 14 July 2015

(C) Springer-Verlag Berlin Heidelberg 2015

\section{Erratum to: Infection (2015) 43:345-352 \\ DOI 10.1007/s15010-015-0771-0}

Due to a transcription error, the name of the ninth author of the original article was rendered incorrectly. His correct name is Georg Dorffner.

The online version of the original article can be found under doi:10.1007/s15010-015-0771-0.

Heinz Burgmann

heinz.burgmann@meduniwien.ac.at

1 Division of Medical and Chemical Laboratory Diagnostics, Department of Laboratory Medicine, Medical University of Vienna, Vienna, Austria

2 Division of Infectious Diseases and Tropical Medicine, Department of Medicine I, Medical University of Vienna, Vienna, Austria

3 Division of Clinical Microbiology, Department of Laboratory Medicine, Medical University of Vienna, Vienna, Austria

4 Section for Artificial Intelligence, Center for Medical Statistics Informatics and Intelligent Systems, Medical University of Vienna, Vienna, Austria 